\title{
A Study on Ammonia Condensation in Bundles of Low-Fin Carbon Steel Tubes
}

\author{
Eaman Hassan Al-Saoub \\ College of Engineering, University of Wasit, Al-Kut, Wasit, Iraq
}

\begin{abstract}
In this paper, the condensation of ammonia was investigated in bundles of horizontal tubes. This tube arrangement is widely used in shell and tube condensers where the vapor condenses on the surface of the tubes. Low-fin carbon steel tubes were considered instead of externally smooth tubes which are typical for ammonia condensers. The influence of varying fin height, number of fins per inch (FPI), and bundle depth were investigated. An analytical model was used to predict the average condensation heat transfer coefficient (HTC) in the bundles of finned tubes. The predictions of the model were verified using published experimental data. Based on Nusselt's theory for smooth tubes, the enhancement factor was determined for the tube bundle to investigate the influence of varying fin geometry. For single tubes, the study found that low-fin tube with fin height of 0.6 mm yields an enhancement factor of 2 . In bundles of low-fin tubes, an enhancement factor up to 2.9 can be obtained. Low-fin tubes show an increasing enhancement factor with the increase in the bundle depth. In addition, the optimum fin height increases with the increase in the bundle depth. For large condensers, low-fin tubes show higher performance than smooth tubes.
\end{abstract}

Keywords:Ammonia, condensation, finned tube, fin height, FPI, bundle depth

\author{
Nomenclature \\ $A$ area, $\mathrm{m}^{2}$ \\ $C_{\mathrm{p}}$ specific heat, $\mathrm{J} \cdot \mathrm{kg}^{-1} \cdot \mathrm{K}^{-1}$ \\ $d_{\mathrm{i}}$ inside tube diameter, $\mathrm{m}$ \\ $d_{\mathrm{r}}$ tube diameter at the fin root, $\mathrm{m}$ \\ $d_{\mathrm{o}}$ outside tube diameter, $\mathrm{m}$ \\ $f$ friction factor, - \\ $g$ acceleration of gravity, $\mathrm{m} \cdot \mathrm{s}^{-2}$ \\ $h$ heat transfer coefficient, $\mathrm{W} \cdot \mathrm{m}^{-2} \cdot \mathrm{K}^{-1}$ \\ $h_{\mathrm{fg}}$ latent heat of vaporization, $\mathrm{J} \cdot \mathrm{kg}^{-1}$ \\ $k$ thermal conductivity, $\mathrm{W} \cdot \mathrm{m}^{-1} \cdot \mathrm{K}^{-1}$ \\ $L$ tube length, $\mathrm{m}$ \\ $\dot{m}$ mass flow rate, $\mathrm{kg} \cdot \mathrm{s}^{-1}$ \\ $N$ number of tube rows, - \\ Pr Prandtl number, - \\ $\dot{Q}$ heat transfer rate, $\mathrm{W}$ \\ Re Reynolds number, - \\ $T$ temperature, $\mathrm{K}$ \\ $U$ overall heat transfer coefficient, $\mathrm{W} \cdot \mathrm{m}^{-2} \cdot \mathrm{K}^{-1}$ \\ Greek symbols \\ $\Delta$ difference \\ $v$ kinematic viscosity, $\mathrm{m}^{2} \cdot \mathrm{s}^{-1}$ \\ $\rho$ density, $\mathrm{kg} \cdot \mathrm{m}^{-3}$ \\ Subscripts \\ $B$ bundle of tubes \\ cw cooling water \\ exp experimental \\ $\mathrm{i}$ inlet \\ Im logarithmic mean \\ Nuss Based on Nusselt's model \\ o outlet \\ pre predicted \\ s saturation \\ w wall \\ Abbreviations \\ FF enhancement factor \\ FPI fins per inch \\ HTC heat transfer coefficient
}

\section{Introduction}

Ammonia is characterized by excellent thermal characteristics such as high latent heat and working pressure which make ammonia one of the desirable refrigerants for hot and rid weather regions. Ammonia is an interesting refrigerant for both direct and indirect refrigeration applications because of its high heat transfer coefficient (HTC). The application of ammonia implies safety preclusions to ovoid the direct contact with it in the gas and the liquid phase. These concerns can be reduced through using ammonia as an indirect working fluid and by reducing the charge of ammonia in the system. For reducing the system charge, HTC should be increased to reduce the surface area of the heat transfer which enables using small size condensers. Here, shell and tube condenser can be utilized where ammonia condenses in the shell while cooling medium passes through the tubes. Plain, low-fin, or enhanced finned tubes can be applied depending on the condenser design. Low-fin tubes have trapezoidal fin cross section with relatively low fin height, and enhanced finned tubes are characterized by additional structuring on the fins. Smooth tubes made of steel or titanium are traditionally used in ammonia systems instead of copper tubes due the chemical reactions which occur between ammonia and copper leading to rapid corrosion of the tube wall. It is to be noted here that titanium and steel have low thermal conductivities amount to about 22 and $50 \mathrm{~W} \cdot \mathrm{m}^{-1} \cdot \mathrm{K}^{-1}$, respectively. These values are very low compared to the thermal conductivity of copper which is about $340 \mathrm{~W} \cdot \mathrm{m}^{-1} \cdot \mathrm{K}^{-}$ ${ }^{1}$. However, the condensation HTC of ammonia on smooth tubes is comparable to that of synthetic refrigerants on enhanced and finned tubes. The high condensation HTC of ammonia compensates the reduction in the condenser duty due to the relatively low thermal conductivity of titanium and steel tubes. Thus, researches and studies for the condensation of ammonia on finned tubes are still limited in literature [1]. In shell and tube condensers, tubes are arranged horizontally in several rows depending on the condenser design. The formed condensate drops due to the gravity from row to row, increases the condensate film 


\section{International Journal of Science and Research (IJSR) \\ ISSN (Online): 2319-7064}

Index Copernicus Value (2013): 6.14 | Impact Factor (2015): 6.391

thickness, and covers much surface are of tubes beneath. Thus, the HTC decreases with the increase in the row number (bundle depth) due to the insulation effect of condensate layer on the tubes. This phenomenon is known as "row effect", "inundation effect", or "bundle effect". For designing of shell and tube condensers, bundle effect should be taken into account to avoid underestimation of active surface area. Researchers pay considerable efforts to estimate bundle effect which depends on many parameters such as the tube geometry, bundle depth, and thermophysical properties of condensing fluid. In bundles of smooth tubes, the condensation HTC decreases dramatically with the bundle depth in comparison to low-fin tubes [2]. The average condensation HTC $h_{\mathrm{B}}$ in the bundle of smooth tubes can be determined based on the model of Nusslet[ 3 ] by

$$
h_{B}=h_{1} N^{-\mathrm{m}}
$$

Where $m=1 / 4$ and $h_{1}$ is the condensation HTC for the first tube in the bundles which is determined by

$$
h_{1}=0.728\left(\frac{g \rho h_{\mathrm{fg}} k^{3}}{v\left(T_{\mathrm{s}}-T_{\mathrm{w}}\right) d_{\mathrm{o}}}\right)^{1 / 4}
$$

where $\rho, v, h_{\mathrm{fg}}$, and $k$ are the density, kinematic viscosity, latent heat, and thermal conductivity of the condensate, respectively. $T_{\mathrm{w}}$ is the temperature of the tube wall, $d_{\mathrm{o}}$ is the tube outside diameter, and $g$ is the acceleration of gravity. Kern [4] suggested using $m=1 / 6$ depending on a comparison with experiments[5]. In bundles of low-fin tubes, the condensation HTC can be calculated using analytical models [6-9]. These models take into account the tube geometry, surface tension effect, number of tubes in the bundle, and the condensate surface curvature. The enhancement results from fins is estimated compared with smooth tubes using enhancement factor EF which can be determined by

$$
\mathrm{EF}=\frac{h_{\mathrm{B}}}{h_{\mathrm{B}, \mathrm{Nuss}}}
$$

Where $h_{\mathrm{B}, \mathrm{Nuss}}$ is determined using the Nusselt model. For low-fin tubes, studies $[\underline{10}, \underline{2}, \underline{11}, \underline{12}]$ confirmed that bundle effect is insignificant which means that the reduction in HTC due to the bundle arrangement is small. Thus, low-fin tubes may perform better than smooth tubes during the condensation of ammonia in tube bundles. The aim of the present work is to investigate the condensation of ammonia in bundles of up to 20 rows of low-fin tubes made of carbon steel. The fin height, fin pitch, and bundle depth are considered in the investigation. An analytical model is used to predict the condensation HTC. This model is described in the following section.

\section{Prediction Model}

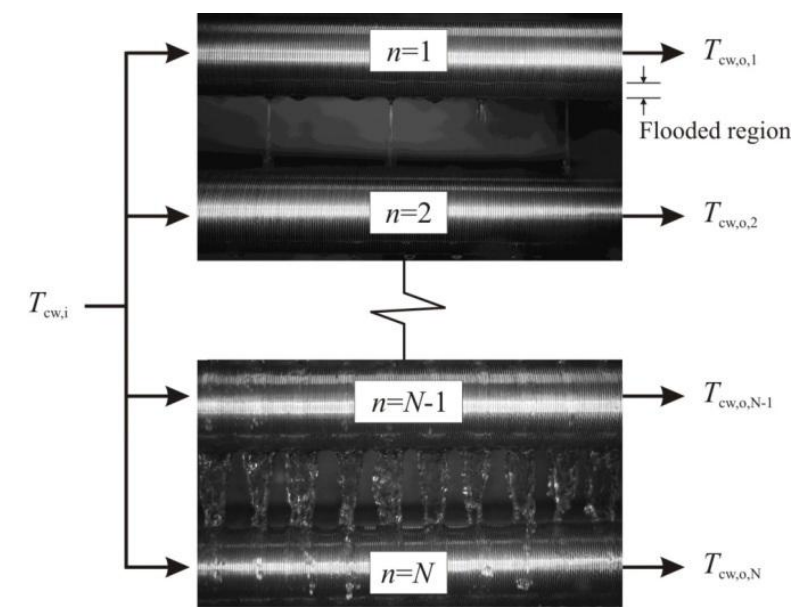

Figure 1: Physical model for a tube bundle

The analytical model for the this investigation was already published in details for single tubes [13] and for tube bundles[]ㅛ. Here, a brief overview is given to describe how the model calculates the HTC in bundles of low-fin tubes. The vapor outside tubes is assumed to be saturated and stagnant, thus the vapor shear is negligible. Inside tubes, cooling water enters with a known temperature $T_{\mathrm{cw}, \mathrm{i}}$ and mass flow rate $\dot{m}$. The condensation occurs on the outside of the tubes in favor of the temperature difference between the saturation temperature $T_{\mathrm{s}}$ and $T_{\mathrm{cw}, \mathrm{i}}$. The formed condensate is driven by gravity and surface tension to drain on the tube surface. An amount of condensate retains on the bottom potion of the tubes where the so called "flooded region" can be recognized, see Figure 1. The model considers each tube in the bundle separately. Beginning from the first tube in the bundle, the tube wall is divided into small annular elements. The heat balance is made for each element to find the elemental heat transfer rate. The heat transfer rate $\dot{q}_{\mathrm{i}}$ from the tube number $i$ in the bundle equals the summation of elemental heat rates from the elements of the tube. For the flooded and the un-flooded regions, the fin tip, fin flank, and the space between fins are considered. The detailed calculation of the elemental heat transfer rate is described in Ref. [13]. The bundle effect is simulated by calculating the mass flow rate from tubes above and distributing it on the tubes below in form of column or sheet mode. The condensation mode depends on the mass flow rate of the condensate and on the vertical spacing between the tubes. This enables the determination of the heat transfer rate for tubes under condensate inundation. Thus, the total heat transfer rate $\dot{Q}$ for a bundle of $N$ tubes is the algebraic summation of heat transfer rates as stated in Eq. 4

$$
\dot{Q}=\sum_{i=1}^{N} \dot{q}_{\text {i }}
$$

The heat balance is made for the cooling water inside each tube to find the outlet cooing water temperature $T_{\mathrm{cw}, \mathrm{o}, \mathrm{i}}$

$$
T_{\mathrm{cw}, \mathrm{o}, \mathrm{i}}=T_{\mathrm{cw}, \mathrm{i}}+\frac{q_{\mathrm{i}}}{\dot{m}_{\mathrm{cw}} C_{\mathrm{p}}}
$$

This enables the determination of the outlet temperature of the cooling water for the bundle $T_{\mathrm{cw}, \mathrm{o}, \mathrm{B}}$ using the average outlet temperature of the tubes as described in the following equation 


\section{International Journal of Science and Research (IJSR) \\ ISSN (Online): 2319-7064}

Index Copernicus Value (2013): 6.14 | Impact Factor (2015): 6.391

$$
T_{\mathrm{cw}, \mathrm{o}, \mathrm{B}}=\frac{\sum_{i=1}^{N} T_{\mathrm{cw}, \mathrm{o}, \mathrm{i}}}{N}
$$

The overall heat transfer coefficient $U$ can be determined by

$$
U=\frac{\dot{Q}}{A \Delta T_{\mathrm{lm}}}
$$

where

$$
\begin{aligned}
\Delta T_{\mathrm{lm}}= & \frac{T_{\mathrm{cw}, \mathrm{o}, \mathrm{B}}-T_{\mathrm{cw}, \text { in }}}{T_{\mathrm{s}}-T_{\mathrm{cw}, \mathrm{o}, \mathrm{B}}} \\
\ln \frac{T_{\mathrm{s}}-T_{\mathrm{cw}, \text { in }}}{A} & =N \pi d_{\mathrm{o}} L
\end{aligned}
$$

and $L$ is the tube length. Using the overall HTC $U$ and the convective HTC for the cooling water $h_{\mathrm{cw}}$, the average condensation HTC for the bundle $h_{\mathrm{B}}$ can be determined by

$$
h_{\mathrm{B}}=\left(\frac{1}{U}-\frac{d_{\mathrm{o}} \ln \left(d_{\mathrm{r}} / d_{\mathrm{i}}\right)}{2 k_{\mathrm{w}}}-\frac{d_{\mathrm{o}}}{d_{\mathrm{i}} h_{\mathrm{cw}}}\right)^{-1}
$$

where $h_{\text {cw }}$ can be calculated by [14].

$$
h_{\mathrm{cw}}=\frac{k_{\mathrm{cw}}}{d_{i}} \frac{(f / 8) f \operatorname{Re}_{\mathrm{cw}} \operatorname{Pr}_{\mathrm{cw}}}{1.07+12.7(f / 8)^{1 / 2}\left(\operatorname{Pr}_{\mathrm{cw}}^{2 / 3}-1\right)}
$$

Here, the friction factor $f$ is expressed by

$$
f=\left[0.79 \ln \left(\mathrm{Re}_{\mathrm{cw}}\right)-1.64\right]^{-2}
$$

In Eq. (10), the tube diameters $d_{\mathrm{o}}, d_{\mathrm{r}}$, and $d_{\mathrm{i}}$ are measured at the fin tip, fin root, and inside tube, respectively, see Figure 2. $k_{\mathrm{cw}}, \mathrm{Re}_{\mathrm{cw}}$, and $\mathrm{Pr}_{\mathrm{cw}}$ are the thermal conductivity, Reynolds number, and Prandtlnumber of cooling water, respectively.

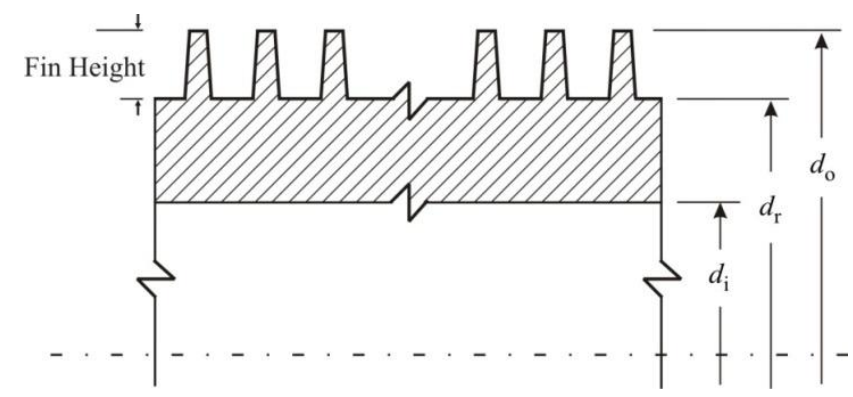

Figure 2: A schematic for a low-fin tube section

\section{Results}

In the following, the predicted enhancement factor is compared with published experimental data at condensing temperatures of $30,35,40$, and $45^{\circ} \mathrm{C}$. Then, the predicted data for single tubes and tube bundles are presented with variable fin heights.

\section{Model verification}

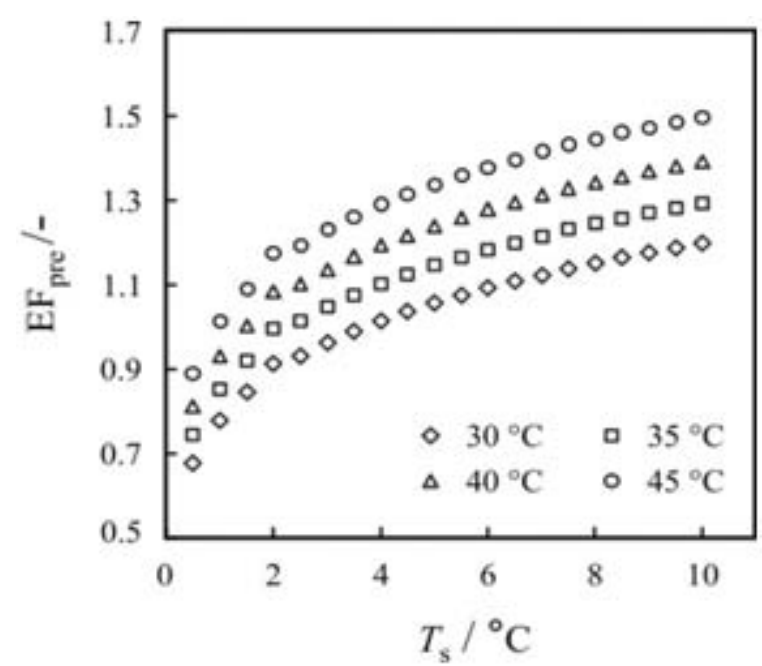

Figure 3: The enhancement factor as a function of saturation temperature

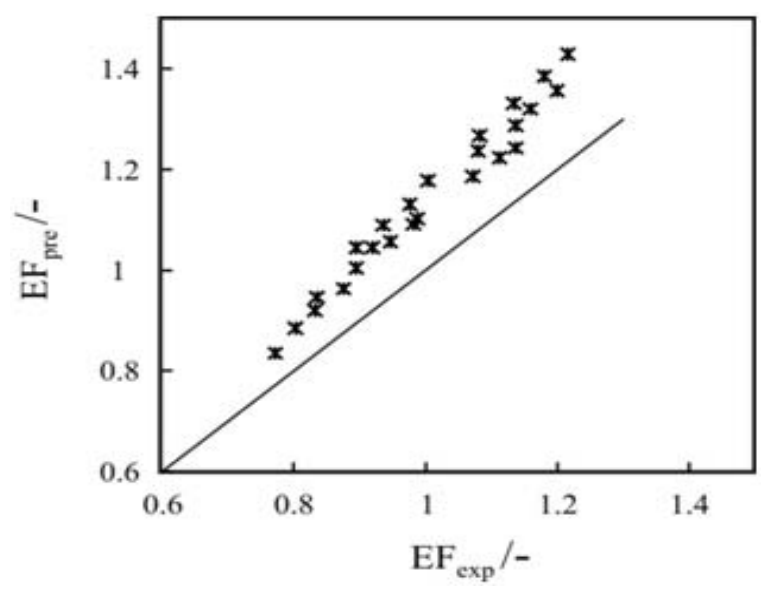

Figure 4: Predicted versus experimental enhancement factor

The prediction of the model is verified using comparison with experimental data from Ref. [1]. These data were collected for the condensation of ammonia on a titanium integral finned tube at saturation temperatures of $30,35,40$, and $45^{\circ} \mathrm{C}$. Figure 3 shows the predicted enhancement factor $\mathrm{EF}_{\text {preas }}$ a function of the subcooling with the saturation temperatures. The enhancement factor $\mathrm{EF}_{\text {pre }}$ increases with the increase in the subcooling and in the condensing temperature. This may be due to the change in the thermophysical properties. The predicted data is compared with the corresponding experimental data from Ref. [1] as shown in Figure 4. Here, the model overprdicted all the experimental data with a mean absolute percentage deviation of $13 \%$. It is to be noted here that the model was also verified using experimental data for R134a and propane condensing on copper and steel tubes $[\underline{8}, \underline{13}]$.

\section{Predicted data}




\section{International Journal of Science and Research (IJSR) \\ ISSN (Online): 2319-7064}

Index Copernicus Value (2013): 6.14 | Impact Factor (2015): 6.391

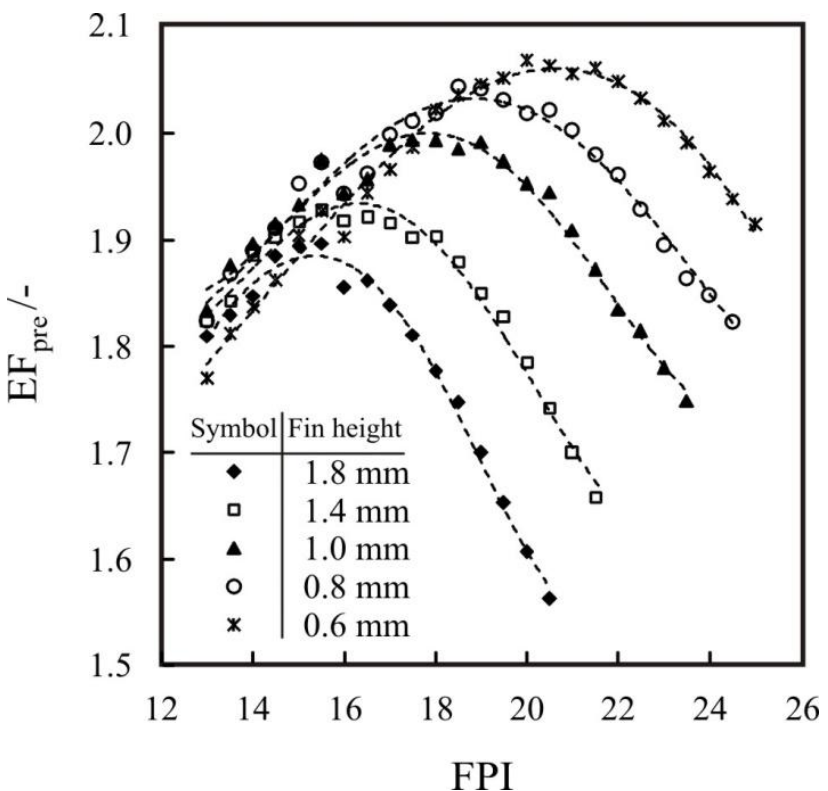

Figure 5: Predicted enhancement factor as a function of FPI for single tubes

For single tubes, $\mathrm{EF}_{\text {pre }}$ is presented as a function of the FPI with fin heights of $0.6,0.8,1,1.4$, and $1.8 \mathrm{~mm}$ as shown in Figure 5. When the FPI increases, the surface area of heat transfer increases, and the retention angle beneath tubes increases as well. The optimum FPI corresponds to the maximum HTC where the increase in the surface area compensates the drawback of the increase in the retention angle. The value of maximum HTC represents the maximum $\mathrm{EF}_{\text {pre }}$ because the denominator of Eq. 3 is kept constant. $\mathrm{EF}_{\text {pre }}$ increases with the increase in FPI until the optimum value where the maximum HTC can be obtained. After the optimum value, $\mathrm{EF}_{\text {pre }}$ decrease with the increase in FPI. $\mathrm{EF}_{\text {pre }}$ increases with the decrease in fin height. For all the date, the optimum value is found with fin height of $0.6 \mathrm{~mm}$.

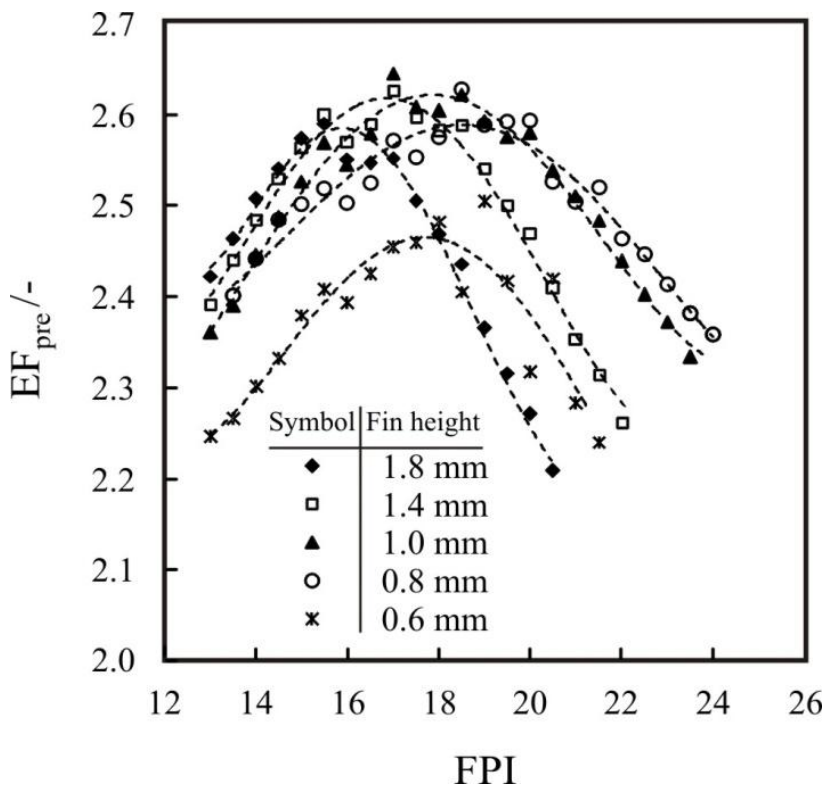

Figure 6: Predicted enhancement factor as a function of FPI for a bundle of ten tubes

Figure 6 shows the $\mathrm{EF}_{\text {pre }}$ as a function of FPI for bundles of ten tubes with variable fin heights. Considering the reduction of HTC due to the bundle arrangement for both smooth and finned tubes, $\mathrm{EF}_{\text {pre }}$ is higher for all fin heights in comparison to single tubes. For this case, the reduction in the absolute value of HTC for low-fin tubes is much smaller than the reduction in HTC for smooth tubes. The tubes with $0.6 \mathrm{~mm}$ fin heights yield the worst performance among the tubes while the maximum $\mathrm{EF}_{\text {pre }}$ may be found with 0.8 or $1.0 \mathrm{~mm}$ fin height in the range of FPI between 16 and 19.

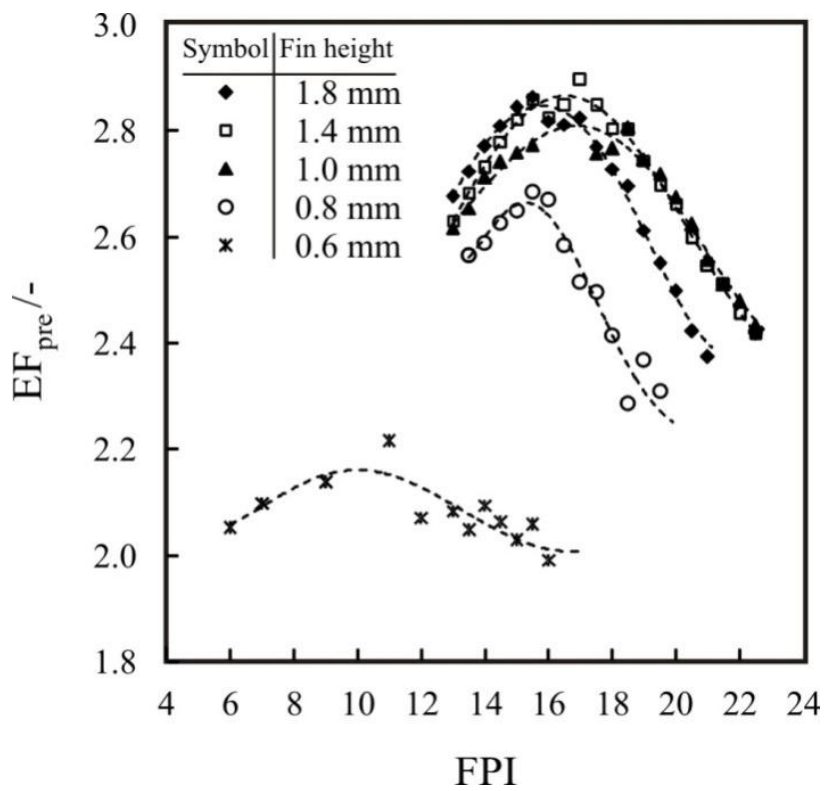

Figure 7: Predicted enhancement factor as a function of FPI for a bundle of twenty tubes

For bundles of 20 tubes, the $\mathrm{EF}_{\text {pre }}$ is higher as shown in Figure 7 compared to bundles of 10 tubes. The optimum $\mathrm{EF}_{\text {pre }}$ is found with fin heights of 1.4 and $1.8 \mathrm{~mm}$ and within the range of FPI between 16 and 18 .

\section{Conclusions}

The condensation of ammonia was investigated for single tubes and for bundles of 10 and 20 tubes made of carbon steel. The influence of the fin height and the FPI on the condensation enhancement factor is taken into consideration. For single tubes, fin height of $0.6 \mathrm{~mm}$ shows an enhancement factor of 2. For tube bundles, optimum fin height increases with the increase in the bundle depth and an enhancement factor up to 2.9 can be obtained. Based on smooth tubes, low-fin tubes show an increasing enhancement factor with the increase in the bundle depth. This can be of interest for designers to utilize low-fin tubes instead of smooth tubes in large condensers of ammonia.

\section{References}

[1] Fernández-Seara, J., Uhía, F.J., Diz, R.: Experimental analysis of ammonia condensation on smooth and integral-fin titanium tubes. International Journal of Refrigeration 32(6), 1140-1148 (2009). doi:http://dx.doi.org/10.1016/j.ijrefrig.2009.01.026

[2] Murase, T., Wang, H.S., Rose, J.W.: Effect of inundation for condensation of steam on smooth and enhanced condenser tubes. International Journal of Heat and Mass Transfer 49(17-18), 3180-3189 (2006). 
doi:http://dx.doi.org/10.1016/j.ijheatmasstransfer.2006. 02.003

[3] Nusselt, W.: Die berflächenkondensation des Wsserdampfes. Z. Vereins Dt. Ing. 60, 541-546 and 569-575 (1916).

[4] Kern, D.Q.: Mathematical development of loading in horizontal condensers. AIChE 4(2), 157-160 (1958).

[5] Marto, P.J., Wanniarachchi, A.S.: The use of wirewrapped tubing to enhance steam condensation in tube bundles. Heat Transfer in Heat Rejection Systems, ASME-HTD 37, 9-16 (1984).

[6] Honda, H., Nozu, S.: A prediction method for heat transfer during film condensation on horizontal low integral-fin tubes. Journal of Heat Transfer 109 (1), 218-225 (1987).

[7] Murata, K., Abe, N., Hashizume, K.: Condensation heat transfer coefficient in a bundle of horizontal integral-fin tubes. In: Proceedings of the 9th Int. Heat Transfer Conf. 1990, pp. 259-264

[8] Al-Badri, A.R.: Element-by-Element Prediction Model of Condensation Heat Transfer in Bundles of Horizontal Integral Finned Tubes. Friedrich-Alexander-University Erlangen-Nuremberg (2014)

[9] Al-Badri, A.R., Rausch, M.H., Leipertz, A., Fröba, A.P.: Effect of fin pitch, fin height, and bundle depth on condensation of R134a, R1234yf, and R1234ze in bundles of integral finned tubes. In: Proceedings of the DKV-Conference, Duesseldorf, Germany 2014

[10] Gstöhl, D.: Heat Transfer and Flow Visualization of Falling Film Condensation on Tube Arrays with Plain and Enhanced Surfaces. Ph.D. Thesis, EPFL Lausanne (2004)

[11]Ji, W.-T., Zhao, C.-Y., Zhang, D.-C., He, Y.-L., Tao, W.-Q.: Influence of condensate inundation on heat transfer of R134a condensing on three dimensional enhanced tubes and integral-fin tubes with high fin density. Applied Thermal Engineering 38(0), 151-159 (2012).

doi:http://dx.doi.org/10.1016/j.applthermaleng.2012.01. 029

[12] Gebauer, T., Al-Badri, A.R., Gotterbarm, A., Hajal, J.E., Leipertz, A., Fröba, A.P.: Condensation heat transfer on single horizontal smooth and finned tubes and tube bundles for R134a and propane. International Journal of Heat and Mass Transfer 56(1-2), 516-524 (2013).

doi:http://dx.doi.org/10.1016/j.ijheatmasstransfer.2012. 09.049

[13] Al-Badri, A.R., Gebauer, T., Leipertz, A., Fröba, A.P.: Element by element prediction model of condensation heat transfer on a horizontal integral finned tube. International Journal of Heat and Mass Transfer 62(0), 463-472 (2013). doi:http://dx.doi.org/10.1016/j.ijheatmasstransfer.2013. 03.015

[14] Petukhov, B.S.: Heat Transfer and Friction in Turbulent Pipe Flow with Variable Physical Properties. Adv. Heat Transfer 6, 503-564 (1970). 